\title{
Towards the Development of a Mobile Application in Movement Competency Training Grounded on the User-Centered Design Model: The Case of a State University in the Philippines
}

\author{
https://doi.org/10.3991/ijim.v16i03.26447 \\ Julius Ceazar G. Tolentino ${ }^{(凶)}$, John Paul P. Miranda, Rodel B. Punzalan, \\ Jomari C. Manalang, Lovely Kate S. Hermogenes, Jayson T. Mallari \\ Don Honorio Ventura State University, Pampanga, Philippines \\ jcgtolentino@dhvsu.edu.ph
}

\begin{abstract}
The corona-virus disease (COVID)-19 pandemic has caused extreme disruption in the delivery of instruction in many educational institutions all over the world. However, this circumstance may not only be a challenge but also an opportunity to foster learning through exploration of various technologies that can be developed, more specifically in a course characterized with a strong skills-based orientation such as physical education (PE). Therefore, the aim set in this study was to develop a mobile application for Movement Competency Training (MCT) grounded on the User-Centered Design Model. This descriptive mixed-method research started with a preliminary needs assessment analysis which was participated by 121 Filipino students enrolled in the MCT course and ten (10) PE teachers. Results revealed the skills that require a higher degree of proficiency such as non-locomotor skills, locomotor, and mobility skills. Also, the majority of the respondents are mobile phone users which justified the adoption of mobile instruction and the development of an application for MCT. Moreover, indicated in this research was the preference of the intended users in terms of design and interface that led to the development of the mobile application and had specified the requirements based on the users' needs. The initial assessment of the developed application indicated a highly acceptable level of functional suitability, usability, and portability by the student-respondents. A field testing of the application may be recommended to determine its effectiveness in mastering the skills in MCT independently.
\end{abstract}

Keywords - mobile application, user-centered design, physical education, movement competency training, flexible learning

\section{$1 \quad$ Introduction}

To provide solutions to schools and university closures, in March 2020, the United Nations Educational, Scientific, and Cultural Organization [1] called the attention of all higher education officials around the world to facilitate the development of emergency responses and partake in the establishment of strategies to provide alternatives in sustaining the delivery of quality education despite global closures due to the threat of the 
coronavirus disease (COVID)-19 pandemic. While lockdowns are enforced globally, countries have been administering remote education programs in exploring alternative ways to provide continuous education using technologies even before and during the pandemic [2]-[5]. In higher education settings, for one, universities were encouraged to employ online learning which is based on three educational modalities, such as synchronous, asynchronous, and hybrid learning environments [3]. Moreover, in the Middle East and North Africa (MENA), about $28 \%$ of the countries from this region used TV and radio, while almost $40 \%$ implemented online education, and $22 \%$ utilized both online and broadcasting media as their option [5].

The existence of different mobile applications in different fields of education makes information processing quicker. Through this, lessons can be visualized in real-time on the students' mobile devices [6], [7], but employing this at large may still require a considerable degree of scientific evidence to foster motivation in learning [8]. According to Zhu and Dragon [9], using mobile technology for physical education might not be effective in improving the students' physical activity level in just a short duration of time, especially when it has no direct physical activity prompt. With that, teachers and students should allot extensive time to properly integrate mobile technologies.

Despite all the pressing challenges that the pandemic has brought about, the education sector must remain timely and relevant. They are expected to surpass all these hurdles through the development of alternative learning modalities to provide learning continuity [10]. Teachers and learners must work collaboratively and provide each other a great understanding to bring harmony in adopting these new flexible learning modalities like online and distance education.

\subsection{Mobile learning}

Mobile learning, also known as M-learning, is an educational content that is developed on mobile devices, such as smartphones, tablets, and anything - from podcasts to full e-Learning courses. Crompton and Burke [11] stated that most of the adults in this generation own more than one mobile device. The huge demography of mobile device owners is between 18-29 years old which is also the typical age of college students. Furthermore, Shyshkanova et al. [12] claimed that students were motivated to use mobile applications in education. Mobile applications made the learning process more dynamic, natural, and psychologically comfortable for the students as they enhance students' motivation to be engaged in lifelong learning.

According to Sattarov and Khaitova [13], the use of mobile learning platforms may be a feasible option for university students. There are now more opportunities for formal and informal learning within and without the classroom. We already have access to so much information at any time and from everywhere. In addition to that, mobile technologies can transform education if they are planned and implemented in a way that is important to the social and cultural context of learning. However, mobile technology's use, application, and design in the global educational environment face technical and sociocultural challenges [14]. Faculty members in higher education should think about how mobile learning will help them extend their learning outside the classroom [11]. The evolution of technology-mediated teaching and learning has progressed to mobile technologies. It not only efficiently communicates with people in information-driven communities, but it also allows for spontaneous, social, informal, and 
situated learning [15]. Ligi and Raja [16] stated that researchers, teachers, and corporations developing educational systems and teaching resources have also shown interest in this emerging m-learning technology. M-Learning facilitates a modern training and learning mechanism to improve students' learning and school experience. Moreover, students can do more through their learning process by using mobile devices and wireless technologies in modern learning environments. In addition, the mobile learning experience can provide students with new learning experiences, enhancing their ability to study at any time and in any place.

With that, the new learning opportunities offered by mobile devices would motivate students. Although the literature indicates positive implications of mobile learning in the teaching and learning process, little is written on developmental studies that considered critical topics from the perspective of students in the revitalized tertiary physical education program in the Philippines. Moreover, it would be interesting to consider a user-centered approach in the development of a mobile application that could be relevant to a flexible learning modality within the context of the pandemic and beyond. Therefore, this study proposed a user-centered mobile application in movement competency training to assist students in learning and applying movement skills under a flexible learning environment.

\subsection{Conceptual framework}

The User-Centered Design (UCD) as seen in Figure 1 is a design approach that collectively gathers information about innovation from future users for the development of the innovation [17], [18]. The UCD is being endorsed internationally as a best practice. The UCD processes are applied in ISO documents, ISO 13407, and ISO TR 18529 [19]. According to the survey conducted by Vredenburg et al. [20], it has been seen that UCD effectiveness measurements are lacking, but some common characteristics of an ideal UCD process were not commonly found to be used in some practices, such as involving the user experience throughout the development process, evaluation of the user's satisfaction, and lastly, the most important, considering the totality of user's experience.

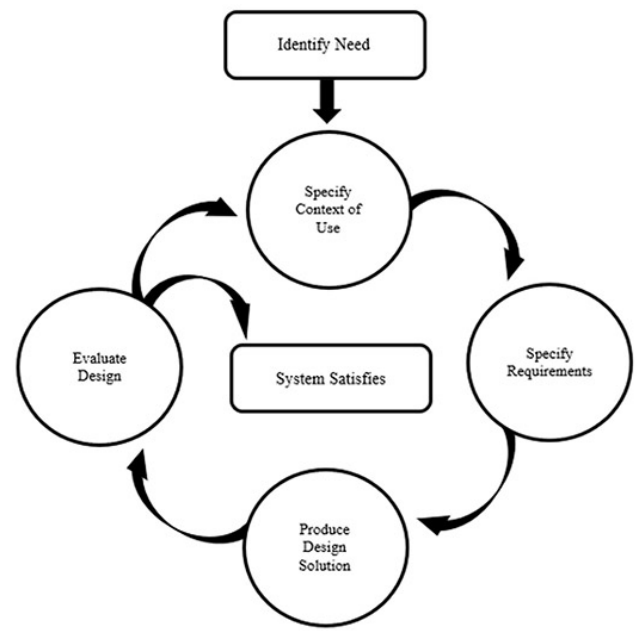

Fig. 1. The user-centered model [17], [18] 


\subsection{Research questions}

The study aimed to answer the following questions:

1. What are the most important skills in preparatory MCT?

2. What are the technology profiles of the respondents?

3. What are the requirements needed for the development and usage of mobile applications in the context of the respondents?

4. What mobile application may be developed based on the results of the needs assessment analysis?

5. What is the assessment of the intended users toward the developed mobile application in terms of its functional suitability, usability, and portability?

\section{Method}

A descriptive mixed-method research design was followed in this study. For the quantitative strand, a preliminary needs assessment analysis (NAA) in the form of a survey was developed based on the literature and the needs of the learners. Needs assessment analysis is vital to extract the bases of the content and context of the educational product [21]. The survey contained the skills as identified in a preparatory MCT course offered to year one physical education major students by a certain state university in the Philippines. The survey assessed the perceived movement competency level of the respondents. For example, if a specific skill is included in the beginning $\mathrm{MCT}$, then it will be included in the content of the developed mobile application. The survey also asked for the respondents' profile; status of technology integration; extent of the availability and accessibility to mobile devices; and their initial perception of the use of mobile applications for PE courses in a distance learning modality. Inputs from the survey shall justify the appropriateness and feasibility of developing mobile applications for learning fundamental movement skills in PE. In terms of the possible elements (e.g., pictures, sounds, text content) and interface (i.e., look and feel) of the application, a series of interviews was conducted with both PE faculty members and students. This qualitative strand of the study was implemented virtually during the strict implementation of community quarantines in the Philippines. Ten (10) faculty members participated in the interview, and 121 students took part in the initial survey. After the development of the mobile application based on the initial findings from the survey, a follow-up survey was conducted. Convenience sampling was used to determine the respondents for the initial assessment of the developed mobile application. An email was sent to the students previously enrolled in the MCT course as identified by the state university containing the invitation to participate, the developed application, and the assessment form. A total of 44 respondents participated and submitted their assessment on whether the developed application was acceptable in its current form. The application was assessed through the following criteria: suitability, usability, and portability.

\subsection{Ethical considerations}

In conducting this study, the researchers adhered to various ethical considerations. The data gathering procedures followed the Belmont Report [22] and the Philippine 
Data Privacy Act of 2012. The report generally considers the three (3) basic principles of respect for persons, beneficence, and justice concerning the ethics of research involving human participants.

\section{Results and discussion}

\subsection{Beginning MCT skills (identify need)}

Based on the preparatory course for MCT, there are three (3) fundamental movement skills: non-locomotor, locomotor, and mobility. According to the interview with the faculty, the three fundamental skills are further subdivided into different competencies as listed in Table 1. Preliminary needs assessment analysis showed that beginning subskill with utmost importance for a non-locomotor skill contains five (5) skills, four (4) for locomotor, and five (5) for mobility.

Although most of the student-respondents perceived themselves as highly competent to the subskills of the three (3) fundamental movements of the MCT course, a considerable minority still view themselves as incompetent (IC) to moderately competent (MC). The said skills were confirmed by their PE teachers during unstructured confirmatory interviews as significant content of the preparatory course as these lay the foundation for proficient execution of other forms of physical activities such as exercise, sports, and dances. These were further considered as the initial content of the developed mobile application to particularly assist the minority of the students who are about to develop a higher degree of proficiency across these skills.

Table 1. Respondents' skills in MCT

\begin{tabular}{|l|c|c|l|}
\hline & HC + C (\%) & MC + IC (\%) & \multicolumn{1}{|c|}{ Explanation (M) } \\
\hline \multicolumn{4}{|c|}{ Non-Locomotor Skills } \\
\hline Bracing the core & $92(76 \%)$ & $29(24 \%)$ & Competent (2.84) \\
\hline Dead bug series & $100(83 \%)$ & $21(17 \%)$ & Highly competent (3.16) \\
\hline Rolling & $91(75 \%)$ & $30(25 \%)$ & Competent (2.98) \\
\hline Squat series & $115(95 \%)$ & $6(5 \%)$ & Highly competent (3.50) \\
\hline Plank series & $101(83 \%)$ & $20(17 \%)$ & Highly competent (3.27) \\
\hline \multicolumn{4}{|c|}{ Locomotor Skills } \\
\hline Crawl and creep & $88(73 \%)$ & $33(27 \%)$ & Competent (2.88) \\
\hline Jumping and landing & $101(83 \%)$ & $20(17 \%)$ & Highly competent (3.24) \\
\hline $\begin{array}{l}\text { Linear movement (hop, skip, leap or } \\
\text { bound, leap, jog, run, and backpedal) }\end{array}$ & $104(86 \%)$ & $17(14 \%)$ & Highly competent (3.26) \\
\hline $\begin{array}{l}\text { Lateral movement (slide, crossover, } \\
\text { grape-vine) }\end{array}$ & $94(78 \%)$ & $27(22 \%)$ & Highly competent (3.09) \\
\hline \multicolumn{4}{|c|}{ Mobility Skills } \\
\hline Ankle & $103(85 \%)$ & $18(15 \%)$ & Highly competent (3.17) \\
\hline Hip & $111(92 \%)$ & $10(8 \%)$ & Highly competent (3.27) \\
\hline T-spine & $87(72 \%)$ & $34(28 \%)$ & Competent (2.88) \\
\hline Vertical pull and push & $87(72 \%)$ & $34(28 \%)$ & Competent (2.94) \\
\hline Lifting and throwing & $96(79 \%)$ & $25(21 \%)$ & Highly competent (3.05) \\
\hline
\end{tabular}

Notes: HC - Highly Competent, C - Competent, MC - Moderately Competent, IC - Incompetent. 


\subsection{Respondents' technology profile (specify context of use)}

Out of 121 respondents, $72 \%$ of them mentioned that their teachers have already integrated technology (e.g., PowerPoint, learning management system, Google Drive, etc.) into their courses $(n=87)$. Although, $60 \%$ of respondents also mentioned that no specific learning application was utilized in their classes to enhance learning in PE $(n=73)$. Despite this, the majority of them believed that a mobile application can be useful in the teaching and learning process of PE courses $(n=103)$.

Most of the respondents owned smartphones $(n=113,93 \%)$ and the majority of them ran on the Android operating system (OS) $(n=105,87 \%)$. Few of them also owned laptops $(n=42,35 \%)$, desktop computers $(n=12,10 \%)$, and tablets $(n=4,3 \%)$. Most of them mentioned that they have used smartphones for their learning $(n=100,83 \%)$, and it is their most preferred device for learning $(n=87,72 \%)$. Since most of them owned smartphones as compared to other devices, this finding is consistent with that of Miranda et al. [23] and GMA News Online [24]. When the respondents were asked about their preference on using their smartphones for a mobile learning application for MCT, more than half of them believed that doing such will help them, including their teachers, to further enhance the teaching and learning process $(n=66,55 \%)$. These findings affirm that the utilization of smartphones for both learning and teaching among Filipino students was common [25]. Furthermore, the usage of smartphones was perceived to be useful in different aspects not only in the teaching and learning process but also in other daily activities [25], [26].

When asked about their preference in terms of the design elements and interface of a mobile application for MCT, the respondents specifically mentioned that it should have simple navigation $(n=96,79 \%)$ and should use offline video-based content $(n=97,80 \%)$. They specifically made mention the importance of the availability of offline video-based content as most of the respondents cannot connect to the internet just to stream them online. They further mentioned that during face-to-face classes, the availability of internet access in the university is very limited - a common problem experienced by most students in the country [27]. Another reason for this was the inadequate internet infrastructure which affects both the speed and cost in the Philippines [28]-[31].

\subsection{Development and usage of mobile applications for MCT (specify requirements)}

Since most of the respondents owned and have used their smartphones for learning, the application ran on Android OS. It was developed using C\# programming language and Unity environment—a cross-platform engine for developing games and applications. The content of the application was specifically made to demonstrate the identified MCT skills. Each content (i.e., text information, videos, and knowledge assessment) was validated and meticulously checked by faculty members before their addition to the application.

\subsection{The MCT mobile application (produce design solution)}

Figure 2 shows that the application, after startup, asks for the name of the user before proceeding to the homepage. The home page consists of three main parts: Lesson, 
Training Exercise, and Settings. The Lesson part of the system when clicked (as seen in Figure 3), shows the three identified skills (i.e., non-locomotor, locomotor, and mobility). The training exercise includes a premade standard sequence of exercises and options for arrangement and customization (Figure 4).
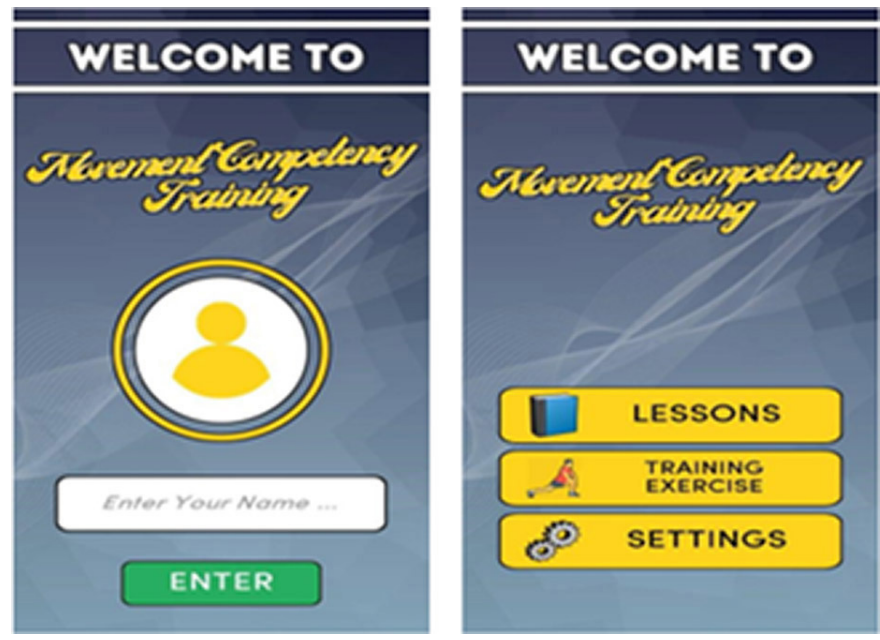

Fig. 2. Welcome and homepage screen

The Lesson part of the application specifically includes standard instructions that can be followed by a user. The functionality is a must-have within the application according to both faculty and students. During the interview, the faculty respondents believed that if each step was specifically worded and visualized at the same time, it can help them in teaching a specific skill. They further mentioned that this feature is needed due to the faculty-student ratio of MCT courses. At the same time, the students will be able to review and practice each step at a slower pace. Sound settings, as well as information about the learning outcome of each skill as well as PAR-Q+ assessment, reside in the Settings section.
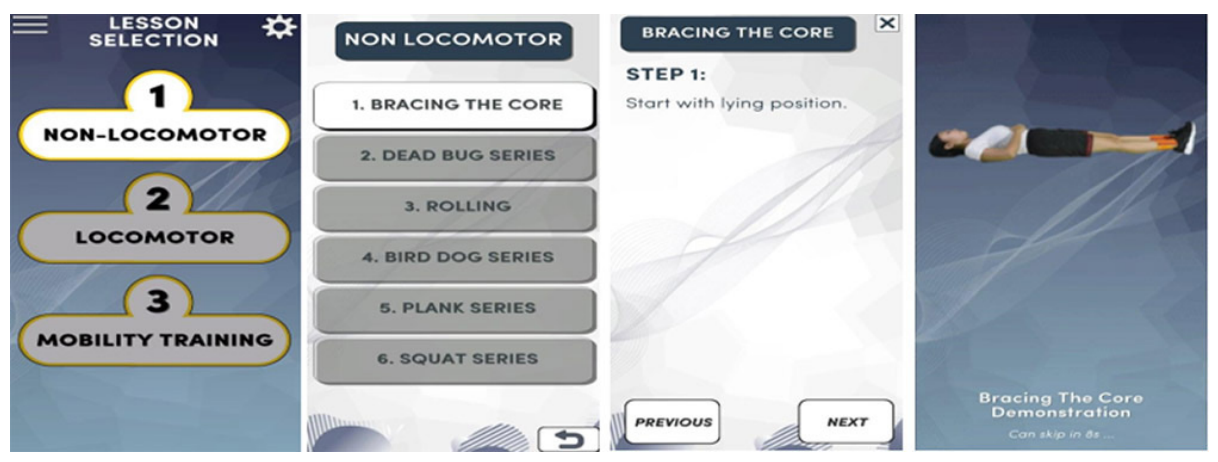

Fig. 3. Lesson selection and skill tutorial 
On the other hand, a user can decide whether to choose a standard practice regimen to master a specific fundamental MCT (i.e., non-locomotor, locomotor, movement) or customize which specific skills to learn first. As seen in Figure 4, the customization also includes the option to change the practice duration of each skill. The application also provides the user the option to arrange the skills per training exercise (maximum of 5 customizations). This feature was added as faculty respondents mentioned that some students tend to master a specific skill before others. Some skills also take time to master and sometimes it also depends on each student. At the end of each skill practice, the application will ask the user to personally rate themselves on how difficult each skill using a 5-point scale from easy to difficult. This feature was added so that the user may review what skills they previously found easy or difficult which they can use when deciding on what to practice again or during customization.
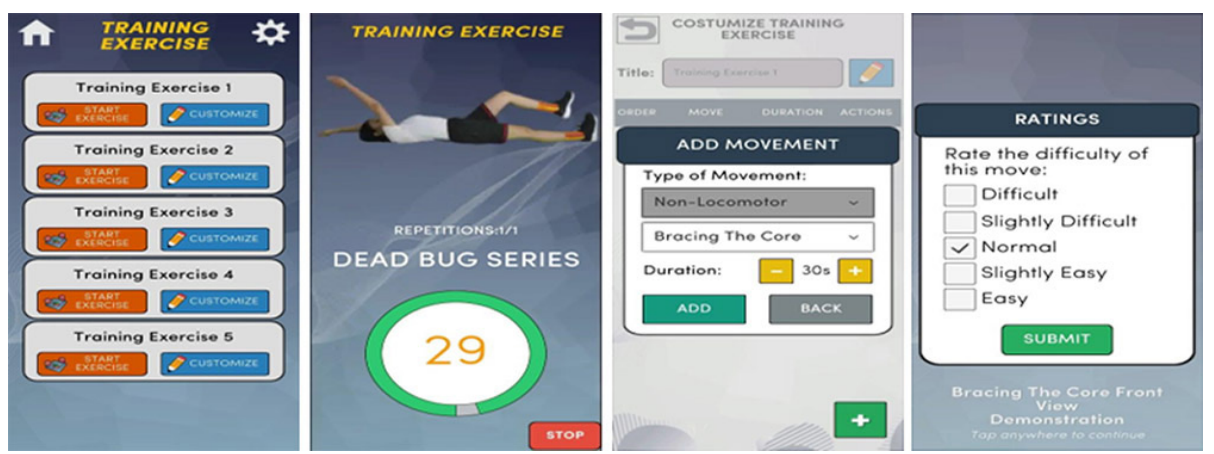

Fig. 4. Training exercise and customization

\subsection{Initial assessment of the MCT mobile application (evaluate design)}

The initial assessment of 44 respondents ( 21 males and 23 females) indicates that the application was functionally suitable $(M=4.70)$, usable $(M=4.61)$, and portable $(M=4.53)$ in their learning context (Table 2). Specifically, in terms of the functional suitability of the application in MCT, respondents believed that the application helps them to learn $(M=4.70)$ and perform MCT skills properly $(M=4.66)$ and appropriately $(M=4.75)$. For its usability, the application was considered user-friendly $(M=4.70)$, has a neat interface $(M=4.45)$, and provides better visualization of the actual movement needed to perform each skill $(M=4.68)$. Furthermore, the respondents made mention that the application was easy to install $(M=4.39)$, can run anytime and anywhere using an android smartphone $(M=4.68)$, and does not require heavy device resources $(M=4.64)$. When asked if they would consider the developed application as a better alternative in learning the MCT skills in general, most of them strongly agreed to the idea $(M=4.45)$.

When the assessment scores of the respondents were compared based on their sex group using a t-test, the overall functional suitability of the application showed that the respondents have statistically significant differences when grouped according to their 
sexes $(t(42)=-3.28, p=0.03)$. In particular, the males $(M=4.88)$ have evaluated the application slightly higher than their female peers $(M=4.51)$. Also, there is no statistically significant difference in terms of the usability and portability of the application based on the scores of the respondents between males and females.

Table 2. Summary of respondents' assessment to the MCT application

\begin{tabular}{|l|c|l|}
\hline Criteria & $\boldsymbol{M}$ & \multicolumn{1}{c|}{ Explanation } \\
\hline Functional suitability & 4.70 & Highly acceptable \\
\hline Usability & 4.61 & Highly acceptable \\
\hline Portability & 4.53 & Highly acceptable \\
\hline
\end{tabular}

Notes: 4.51-5.0 (Highly Acceptable); 3.51-4.50 (Moderately Acceptable); 2.51-3.50 (Acceptable); $1.51-2.50$ (Slightly Acceptable); 1.0-1.51 (Not Acceptable).

\section{Conclusion}

Several considerations were identified before the development of the MCT application. Initial findings showed that there are 14 most important skills for preparatory MCT. It showed that despite the high number of respondents who perceived themselves as either competent or highly competent, a considerable number of students still believe that they are not competent enough to perform the fundamentals skills in MCT. For this reason, an application was developed to help current and future students to acquire a higher level of competency in preparatory MCT.

Another consideration is that most of the respondents said that smartphones are their most available device at the moment. They preferred to use it for their learning despite some of them having the option to opt for other devices - making the main reason why the MCT application was specifically created for smartphones with Android OS. The respondents also highlighted that they want an application that is simple yet easy to navigate as well as having the capability of previewing step-by-step procedures of skill without the need to access the internet. The ability to customize the training exercise within the application was also added to further enhance the teaching and learning process for MCT. Initial assessment of the developed application showed that the application is highly acceptable in terms of the three criteria: functional suitability, usability, and portability.

\section{$5 \quad$ Future works}

Since the developed MCT application was not fully evaluated due to existing movement restrictions placed all over the Philippines caused by the COVID-19 pandemic, field testing accompanied by user-acceptance testing to its intended users is warranted when face-to-face sessions are allowed. The field testing will better validate the applicability to learn the MCT skills in both distance learning and classroom setting. For future works, the inclusion of other PE courses which require strict step-by-step procedures where proper visualization can greatly help should be added within the application. 
Making the application automatically recommend the skills and time to practice a specific or series of skills is also worth pursuing. Future studies may replicate the process mentioned in this study to develop similar applications for other courses.

\section{Acknowledgment}

The authors are indebted to the respondents of the study and the Don Honorio Ventura State University for funding and extending support to this endeavor.

\section{$7 \quad$ References}

[1] United Nations Educational Scientific and Cultural Organization, "UNESCO's Support: Educational Response to COVID-19," 2021. https://en.unesco.org/covid19/educationresponse/support (accessed Aug. 23, 2020).

[2] J. J. B. Joaquin, H. T. Biana, and M. A. Dacela, "The Philippine Higher Education Sector in the Time of COVID-19," Front. Educ., vol. 5, p. 208, 2020, doi: https://doi.org/10.3389/ feduc. 2020.576371

[3] A. Perveen, "Synchronous and Asynchronous E-Language Learning: A Case Study of Virtual University of Pakistan," Open Prax., vol. 8, no. 1, pp. 21-39, 2016, doi: https://doi. org/10.5944/openpraxis.8.1.212

[4] S. Poultsakis, S. Papadakis, M. Kalogiannakis, and S. Psycharis, "The management of Digital Learning Objects of Natural Sciences and Digital Experiment Simulation Tools by Teachers," Adv. Mob. Learn. Educ. Res., vol. 1, no. 2, pp. 58-71, 2021, doi: https://doi. org/10.25082/AMLER.2021.02.002

[5] E. Vegas and R. Winthrop, "Global Education: How to Transform School Systems?," 2020. Accessed: Aug. 24, 2021. [Online]. Available: https://www.brookings.edu/research/ global-education-how-to-transform-school-systems/

[6] E. Ozdalga, A. Ozdalga, and N. Ahuja, "The Smartphone in Medicine: A Review of Current and Potential use among Physicians and Students," J. Med. Internet Res., vol. 14, no. 5, pp. 1-14, 2012, doi: https://doi.org/10.2196/jmir.1994

[7] Y. M. Tsarapkina, N. V. Dunaeva, and A. M. Kireicheva, "Using BYOD Technology in Education using the Lecture Racing Mobile Application as an Example," Comput. Sci. Educ., no. 9, pp. 56-64, 2019, doi: https://doi.org/10.32517/0234-0453-2019-34-9-56-64

[8] S. Papadakis, "Advances in Mobile Learning Educational Research (A.M.L.E.R.): Mobile Learning as an Educational Reform," Adv. Mob. Learn. Educ. Res., vol. 1, no. 1, pp. 1-4, 2021, doi: https://doi.org/10.25082/AMLER.2021.01.001

[9] X. Zhu and L. A. Dragon, "Physical Activity and Situational Interest in Mobile Technology Integrated Physical Education: A Preliminary Study," Acta Gymnica, vol. 46, no. 2, pp. 59-67, 2016, doi: https://doi.org/10.5507/ag.2016.010

[10] T. Karakose, R. Yirci, and S. Papadakis, "Exploring the Interrelationship between COVID19 Phobia, Work-Family Conflict, Family-Work Conflict, and Life Satisfaction among School Administrators for Advancing Sustainable Management," Sustainability, vol. 13, no. 15,2021 , doi: https://doi.org/10.3390/su13158654

[11] H. Crompton and D. Burke, "The Use of Mobile Learning in Higher Education: A Systematic Review," Comput. Educ., vol. 123, pp. 53-64, 2018, doi: https://doi.org/10.1016/j. compedu.2018.04.007 
[12] G. Shyshkanova, T. Zaytseva, and O. Frydman, "Mobile Technologies Make Education a Part of Everyday Life," Inf. Learn. Sci., vol. 118, no. 11/12, pp. 570-582, 2017, doi: https:// doi.org/10.1108/ILS-03-2017-0019

[13] A. R. Sattarov and N. F. Khaitova, "Mobile Learning as New Forms and Methods of Increasing the Effectiveness of Education," Eur. J. Res. Reflect. Educ. Sci., vol. 7, no. 12, pp. 1169-1175, 2019, [Online]. Available: http://www.idpublications.org/wp-content/uploads/2019/12/Full-Paper-MOBILE-LEARNING-AS-NEW-FORMS-AND-METHODS-OF-INCREASING-THE-EFFECTIVENESS.pdf

[14] J. Keengwe and M. Bhargava, "Mobile Learning and Integration of Mobile Technologies in Education," Educ. Inf. Technol., vol. 19, no. 4, pp. 737-746, 2014, doi: https://doi. org/10.1007/s10639-013-9250-3

[15] A. Vishwakarma, "Benefits and Challenges of Mobile Learning in Education," in Promoting Active Learning through the Integration of Mobile and Ubiquitous Technologies, J. Keengwe, Ed. IGI Global, 2015, pp. 24-36. https://doi.org/10.4018/978-1-4666-6343-5. $\underline{\operatorname{ch} 002}$

[16] L. B and B. W. Dharma Raja, "Mobile Learning in Higher Education," Int. J. Res. -GRANTHAALAYAH, vol. 5, no. 4, pp. 1-6, 2017, doi: https://doi.org/10.29121/granthaalayah.v5.i4(SE).2017.1942

[17] A. R. Dopp, K. E. Parisi, S. A. Munson, and A. R. Lyon, “A Glossary of User-Centered Design Strategies for Implementation Experts,” Transl. Behav. Med., vol. 9, no. 6, pp. 1057-1064, 2019, doi: https://doi.org/10.1093/tbm/iby119

[18] R. Kling, "The Organizational Context of User-Centered Software Designs," MIS Q., vol. 1, no. 4, pp. 41-52, 1977, doi: https://doi.org/10.2307/249021

[19] J.-Y. Mao, K. Vredenburg, P. W. Smith, and T. Carey, "The State of User-Centered Design Practice," Commun. ACM, vol. 48, no. 3, pp. 105-109, 2005, doi: https://doi. org/10.1145/1047671.1047677

[20] K. Vredenburg, J.-Y. Mao, P. W. Smith, and T. Carey, "A Survey of User-Centered Design Practice," in Proceedings of the SIGCHI Conference on Human Factors in Computing Systems, pp. 471-478, 2002, doi: https://doi.org/10.1145/503376.503460

[21] J. C. G. Tolentino, J. P. P. Miranda, V. G. M. Maniago, and V. B. Sibug, "Development and Evaluation of Localized Digital Learning Modules for Indigenous Peoples' Health Education in the Philippines," Univers. J. Educ. Res., vol. 8, no. 12, pp. 6853-6862, 2020, doi: https://doi.org/10.13189/ujer.2020.081251

[22] National Commission for the Protection of Human Subjects of Biomedical and Behavioral Research, "The Belmont Report," 1979. [Online]. Available: https://www.hhs.gov/ohrp/ sites/default/files/the-belmont-report-508c FINAL.pdf

[23] J. P. P. Miranda et al., "Development of INSVAGRAM: An English Subject-Verb Agreement Mobile Learning Application," Int. J. Emerg. Technol. Learn., vol. 16, no. 19, p. 219 , 2021, doi: https://doi.org/10.3991/ijet.v16i19.24071

[24] GMA News Online, "Most Pinoy students use smartphones for distance learning - SWS," 2021. https:/www.gmanetwork.com/news/news/nation/777920/most-pinoy-students-usesmartphones-for-distance-learning-sws/story/ (accessed Feb. 03, 2021).

[25] R. M. Cacho, "Student teachers' smartphone academic uses and preferences: Perspectives for mobile-aided pedagogy," in 2016 14th International Conference on ICT and Knowledge Engineering (ICT\&KE), pp. 57-61, 2016, doi: https://doi.org/10.1109/ICTKE.2016.7804099

[26] L. Pradal-Cano et al., "Using Mobile Applications to Increase Physical Activity: A Systematic Review," International Journal of Environmental Research and Public Health, vol. 17, no. 21. 2020, doi: https://doi.org/10.3390/ijerph17218238 
[27] R. A. Pugoy, C. Habito, and R. Figueroa, "Hybrid Online/Offline Mobile Solutions for Accessing Open Educational Resources in Areas with Poor Internet Connectivity," Asian Assoc. Open Univ. J., vol. 11, no. 2, pp. 182-196, 2016, doi: https://doi.org/10.1108/ AAOUJ-09-2016-0030

[28] Surfshark, "Digital Quality of Life Index 2020," 2020. [Online]. Available: https://surfshark. com/dql2020-slides.pdf

[29] ABS-CBN News, "DICT official on current technology infrastructure in PH: 'Kulang na kulang," 2020. https://news.abs-cbn.com/business/05/02/20/dict-official-on-current-technology-infrastructure-in-ph-kulang-na-kulang (accessed Feb. 05, 2020).

[30] The Citizen Lab, "An Overview of Internet Governance and Infrastructure in the Philippines,” 2017. [Online]. Available: https://citizenlab.ca/wp-content/uploads/2017/04/ An-Overview-of-Internet-Infrastructure-and-Governance-in-the-Phillippines.pdf

[31] R. A. Salac and Y. S. Kim, "A Study on The Internet Connectivity in The Philippines," Asia Pacific J. Bus. Rev., vol. 1, no. 1, pp. 67-88, 2016, doi: https://doi.org/10.20522/ APJBR.2016.1.1.67

\section{Authors}

Julius Ceazar G. Tolentino is the chairperson of the Department of Physical Education and the concurrent coordinator of the Research Management Unit of the College of Education at the Don Honorio Ventura State University, Bacolor, Pampanga, Philippines. Educational technology, physical education, and cultural studies are the areas of interest in his research works.

John Paul P. Miranda is a faculty member at Don Honorio Ventura State University (DHVSU) Mexico Campus - College of Computing Studies. His publications are in data science, data mining, computer science/IT education, and software development.

Rodel B. Punzalan, Jomari C. Manalang, Lovely Kate S. Hermogenes, and Jayson T. Mallari are pre-service teachers in the Department of Physical Education of the College of Education at the Don Honorio Ventura State University, Bacolor, Pampanga, Philippines.

Article submitted 2021-08-23. Resubmitted 2021-11-29. Final acceptance 2021-12-06. Final version published as submitted by the authors. 